\title{
IMPLEMENTATION AND EVALUATION OF THE CLINICAL PATHWAY FOR THE DIAGNOSIS AND TREATMENT OF ACUTE CORONARY SYNDROME
}

Bishnu Mani Dhital, ${ }^{1 *}$ Ou Yang Mao, ${ }^{2}$ Shyam Raj Regmi, ${ }^{1}$ Sudhir Regmi ${ }^{1}$

${ }^{1}$ Department of Cardiology, Chitwan Medical College, Bharatpur, Chitwan, Nepal

${ }^{2}$ Department of Cardiology, Xiangya Third hospital of Central South University, Changsha, Hunana, China

*Correspondence to: Dr. Bishnu Mani Dhital, Department of Cardiology, Chitwan Medical College, Bharatpur, Chitwan, Nepal.

Email: bishnumd@gmail.com

\begin{abstract}
Background: The clinical pathways have been developed to guide and standardize diagnosis, treatment of certain diseases, optimize smooth patient care, and its application has been proven to regulate the medical practice and to improve the quality of medical care in developed countries. Objective: To analyze and evaluate the diagnosis and treatment of acute coronary syndrome (ACS) after the implementation of clinical pathways and to identify the areas need to be improved in clinical practice in Xiangya Third Hospital of Central South University. Methods: 250 ACS patients, divided into five groups 50 in each, were collected from December 2009 to December 2011, the first group was considered as baseline and compared with other four group. All these data were compared and analyzed with other tertiary hospitals of china. Results: STEMI patients arriving within 12 hours of onset of symptoms was increased $(P<0.05)$, and final diagnosis consistent with cardiac markers was also increased $(P<0.05)$. Use of aspirin, clopidogrel, $\beta$-Blocker, ACEI /ARB, and statin was higher $(P>0.05)$, but the use of clopidogrel and statin was significantly higher $(P<0.05)$ than other hospitals; no significant difference $(P>0.05)$ in Door-to-needle time or Door-to-balloon time, though longer than standard guidelines, but the door-to-needle time was shorter when compared with other hospitals. TIMI risk score of UA/NSTEMI patients and invasive therapy $(\mathrm{PCI})$ was negatively correlated $(r=-0.312, P<0.05)$, and results were similar when compared with other hospitals; high-risk patients increased, but no significant difference in mortality ( $P>0.05)$. Conclusion: Implementation of Clinical pathway may help to improve patient outcome with early invasive and medical therapy.
\end{abstract}

Keywords: Acute coronary syndrome, Clinical pathway, Diagnosis, Risk stratification, Treatment

\section{INTRODUCTION}

Cardiovascular disease has become a global disease with $80 \%$ of the deaths occur in developing countries. ${ }^{1}$ The major burden of death is due to Myocardial Infarction. The number of ACS patients has been increasing and leading to 700,000 premature deaths in China. ${ }^{2}$ Increase in incidence of cardiovascular disease and mortality in china has been documented by Sino-MONICA (Monitoring Trends and Determinants in Cardiovascular Disease) study. ${ }^{3}$

Acute coronary syndrome (ACS) is a spectrum of disease including Unstable Angina (UA), ST-elevation myocardial infarction (STEMI), non-ST-elevation myocardial infarction (NSTEMI).
Treatment of ACS, which include antiplatelet, beta blockers, Stains, Nitrates, ACEI/ ARB and revascularization, have improving outcomes in term of myocardial infarction, heart failure, and death. Antiplatelet, including aspirin which significantly reduces mortality in acute Myocardial infarction; ${ }^{4}$ and its combination with clopidogrel, has shown 20 percent reduction in cardiovascular death, $\mathrm{MI}$ and stroke in both high and low risk patients with UA/NSTEMI. ${ }^{5}$ Patient management strategies are specified according to severity and high mortality risk in ACS. ${ }^{6} \mathrm{PCl}$ has been the gold standard treatment for the acute STEMI, but thrombolytic are still used. Invasive and conservative medical management are two modes of treatment for NSTEMI and unstable angina ${ }^{[7]}$. According to patient perspective, functional status, symptoms burden and health related quality 
of life are the critical outcome. ${ }^{8}$ So the long term outcome in the management of coronary artery disease has been predicted by their health status. ${ }^{9}$

Clinical pathways or integrated care pathways, multidisciplinary management tool which are based on evidence - based medicine for certain group of patients with predictable clinical course. They also include different tasks and intervention, which are defined, optimized and sequenced by hour (emergency department), day (acute care), visit (homecare), and formally carried out by the professionals and specialist.

Even though, there are numerous evidence showing significant reduction in mortality and morbidity in the patients managed according to guidelines and risk stratification protocols; but the many hospitals are not able to confine with evidence based practice, leading to poor outcome. The purpose of the study was to analyze and evaluate the diagnosis and treatment of acute coronary syndrome after the implementation of clinical pathway, and to identify potential areas for improvement in ongoing clinical practice in our hospital.

\section{MATERIALS AND METHODS}

\section{Study approval}

All patients gave written and informed consent to participate in the study, which was undergone with the approval of the institutional review and ethical committee of Cardiology Department of third Xiangya Hospital, Central south university. Following ethical approval, permission of the execution of this study and access to the patients and their records were granted.

\section{Methods}

To collect the information from the patient, we adopt standard definition to classify ACS. Acute ST elevation myocardial infarction diagnosis was mainly based on typical chest pain persisting for $>30 \mathrm{~min}$, ST-segment elevation of $>0.2 \mathrm{mV}$ in $>2$ contiguous leads on a standard 12-lead electrocardiogram and elevation of cardiac enzymes, cTroponin-I assay $>0.15 \mathrm{ng} / \mathrm{mL}$, and elevation of serum creatinine kinase (CK)-MB isoenzyme level to greater than twice the upper limit of the normal range; NSTEMI was defined when patient presented with suggestive cardiac symptoms and/or ECG changes (e.g. ST segment depressions and/or $T$ wave changes), and a positive troponin and CK-MB blood test.10 UA defined as when patients presented with suggestive cardiac symptoms, as defined by at least one of the following: new onset angina ( $<2$ months) of at least Canadian Cardiovascular Society Classification (CCSC) class III, prolonged (>20 minutes) rest angina, recent ( $<2$ months) worsening of angina, or angina that occurred within 2 weeks of a previous $\mathrm{MI}$, and transient ST changes with negative cardiac enzyme test. $^{11}$

We set up a quality control team for clinical pathway for acute coronary syndrome. The data of the first consecutive 50 patients with the diagnosis of ACS was collected as baseline from our hospital since December 2009. By observing the clinical pathways for acute coronary syndrome issued by the Ministry of Health, we try to find gaps and area to be fulfilled and improved, and to develop suitable pathway for medical diagnosis and treatment in our hospital.

According to the modified clinical pathways, we continued to collect data of consecutive 50 patients with the diagnosis of ACS as the first group and compared with that of baseline group to find the potential areas of improvement, and then data of next 50 ACS patients was collected, which was compared with the baseline group. At last, with same procedure, patients in four groups, 50 in each, were recruited.

Pathways were implemented as flow-charts and/ or check-lists, maintained as part of the patients' medical record. Then the clinical data of our hospital and some tertiary hospitals of china were compared and analyzed. All data collection ended on December- 2011.

All the patients were diagnosed or suspected cases of ACS according to ischemic symptoms; ECG changes (ST elevation and depression, new left bundle branch block, pathological $\mathrm{Q}$ wave development); elevation of cardiac enzymes, were included. A log of all consecutive patients was maintained.

\section{Data collection}

Data collected in Standard case report forms which included sociodemographic characteristics, risk factors, blood pressure, heart rate, ECG, cardiac 
enzymes, duration of hospital stay, TIMI risk score, time duration of onset of symptoms to hospital arrival, survival at hospital discharge, high risk patients, door-to-needle and balloon time, and final discharge diagnosis consistent with cardiac markers. Similarly, treatment modalities (thrombolysis, $\mathrm{PCl}$, medical management) were collected from our as well as nationwide tertiary hospitals. Detailed interviews and chart abstraction to obtain their demographic, clinical, health status, treatment characteristics were done.

\section{Statistical analysis}

Clinical data were presented as mean + standard deviation (SD) or percentage. Binominal variables were analyzed by chi-square test ( $\chi 2)$. Kruskal-Wallis test was used to compare the TIMI risk score, door to needle and door to balloon time in five groups. Spearman's rank correlation coefficient test was used to test the correlation between TIMI risk score and invasive therapy $(\mathrm{PCI})$. One sample t- test was used to compare the average hospital stay between baseline group and other four groups.

Results were considered significant at $\mathrm{P}<0.05$. Data were analyzed with Statistical Package for the Social Sciences (SPSS) software package (16.0) for windows (SPSS Inc., Chicago, IL, USA).

\section{RESULTS}

\section{Patient characteristics}

Out of 250 patients, 192 (77\%) were males, mean age 63 years, hypertension (55\%), smoking (60\%), diabetes (12\%), dyslipidemia (12\%),CAD (41\%), myocardial infarction (12\%), stroke (6\%) and heart failure (5\%). The mean creatinine level was $90 \mathrm{mg} / \mathrm{dl}$. Mean systolic, diastolic blood pressure and heart rate were $128 \mathrm{mmHg}, 77 \mathrm{mmHg}$, and $76 \mathrm{bpm}$ respectively. Lipid profile are also mentioned in (table1).

\section{Table1. Baseline characteristics of the $\mathbf{2 5 0}$ patients}

\begin{tabular}{|l|l|}
\hline Characteristics & $\mathbf{n}=\mathbf{2 5 0}$ \\
\hline Sociodemographic characteristics & $63.0+11.3$ \\
\hline Mean age (years) & 77.6 \\
\hline Male (\%) & \multicolumn{2}{|l|}{} \\
\hline Medical history & 12.4 \\
\hline Myocardial infarction (\%) & 41.2 \\
\hline Coronary artery disease (\%) & 5.2 \\
\hline Heart failure (\%) & 6.4 \\
\hline Stroke (\%) & \multicolumn{2}{|l|}{} \\
\hline Risk factors & 12 \\
\hline Diabetes Mellitus type 2(\%) & 55.2 \\
\hline Hypertension (\%) & 11.6 \\
\hline Dyslipidaemia (\%) & \multicolumn{2}{|l}{} \\
\hline Smoking status & 60.8 \\
\hline Current (\%) & 13.6 \\
\hline Former (\%) & $128+24$ \\
\hline Presenting condition & $77+13$ \\
\hline Systolic pressure (mmHg) & $76+16$ \\
\hline Diastolic pressure (mmHg) & \\
\hline Heart rate (bpm) & \\
\hline
\end{tabular}


Dhital et al, Journal of Chitwan Medical College 2018; 8(23)

\begin{tabular}{|l|l|}
\hline Creatinine $(\mathrm{mg} / \mathrm{dl})$ & $90.1+51.2$ \\
\hline Cholesterol $(\mathrm{mmol} / \mathrm{l})$ & $4.55+1.07$ \\
\hline LDL $(\mathrm{mmol} / \mathrm{l})$ & $2.80+0.94$ \\
\hline HDL $(\mathrm{mmol} / \mathrm{l})$ & $1.04+0.39$ \\
\hline TG $(\mathrm{mmol} / \mathrm{l})$ & $1.64+1.18$ \\
\hline
\end{tabular}

LDL: Low Density Lipoprotein, HDL: High Density Lipoprotein, TG: Triglyceride.

Table2. Comparison of general characteristics in different groups

\begin{tabular}{|c|c|c|c|c|c|c|c|}
\hline \multirow{2}{*}{ Characteristics } & \multicolumn{5}{|l|}{ Groups } & \multirow{2}{*}{ (Mean) } & \multirow{2}{*}{$\begin{array}{l}\mathrm{P} \\
\text { value }\end{array}$} \\
\hline & Baseline & $\mathrm{I}$ & II & III & IV & & \\
\hline $\begin{array}{l}\text { Duration of hospital } \\
\text { stay (days) }\end{array}$ & $9.88 \pm 1.23$ & $10.9 \pm 1.34$ & $10.62 \pm 0.78$ & $12.08 \pm 0.96$ & $10.38 \pm 1.15$ & 11.2 & 0.000 \\
\hline $\begin{array}{l}\text { TIMI Risk score for } \\
\text { UA/NSTEMI pa- } \\
\text { tients }\end{array}$ & $2.77 \pm 1.68$ & $1.73 \pm 0.93$ & $2.40 \pm 1.35$ & $2.60 \pm 1.07$ & $3.04 \pm 1.09$ & 2.44 & 0.043 \\
\hline High risk patients & 37 & 33 & 46 & 48 & 43 & 42.3 & 0.220 \\
\hline $\begin{array}{l}\text { Survival of patients } \\
\text { at hospital discharge }\end{array}$ & 49 & 43 & 49 & 49 & 47 & 47 & 0.307 \\
\hline \multirow{2}{*}{$\begin{array}{l}\text { High-risk patients } \\
\text { undergoing CAG/ } \\
\text { PCI }\end{array}$} & $70.3 \%$ & $84.8 \%$ & $84.8 \%$ & $81.3 \%$ & $72.1 \%$ & $80.6 \%$ & 0.071 \\
\hline & $(26 / 37)$ & $(28 / 33)$ & $(39 / 46)$ & $(39 / 48)$ & $(31 / 43)$ & & 1 \\
\hline \multirow{2}{*}{$\begin{array}{l}\text { Arrival of STEMI } \\
\text { patients at hospital } \\
\text { within } 12 \text { hours of } \\
\text { onset of symptoms }\end{array}$} & $20.0 \%$ & $31.0 \%$ & $48.6 \%$ & $70.0 \%$ & $71.4 \%$ & $56.1 \%$ & 0.00 \\
\hline & $(2 / 10)$ & $(9 / 29)$ & $(17 / 35)$ & $(28 / 40)$ & $(20 / 28)$ & & \\
\hline $\begin{array}{l}\text { Door-to-needle time } \\
\text { (minutes) }\end{array}$ & $49.50 \pm 19.56$ & $40.80 \pm 23.75$ & $49.25 \pm 25.88$ & $50.92 \pm 19.63$ & $53.70 \pm 22.62$ & 48.7 & 0.784 \\
\hline $\begin{array}{l}\text { Door-to-balloon time } \\
\text { (minutes) }\end{array}$ & 0 & 0 & $257 \pm 53.59$ & $81.75 \pm 30.26$ & $192.33 \pm 56.84$ & 132.77 & 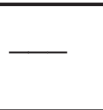 \\
\hline \multirow{2}{*}{$\begin{array}{l}\text { Patients whose final } \\
\text { discharge diagnosis } \\
\text { was consistent with } \\
\text { cardiac biomarkers }\end{array}$} & $60.0 \%$ & $66 . .0 \%$ & $92.0 \%$ & $96.0 \%$ & $86.0 \%$ & $85 \%$ & 0.00 \\
\hline & $(30 / 50)$ & $(33 / 50)$ & $(46 / 50)$ & $(48 / 50)$ & $(43 / 50)$ & & 0 \\
\hline
\end{tabular}

\section{Comparison of general characteristics in different groups}

Average length of hospital stay was longer in four groups (mean - 11days) than baseline group (9.88 days) which was statistically significant $(P=0.000)$. Mean TIMI risk score of four group was also decreased when compare with baseline group $(P=0.043)$. Arrival of STEMI patients at hospital within 12 hours of onset of symptoms was also significantly higher in four groups $(P=0.000)$ when compared with baseline. Patients whose final discharge diagnosis was consistent with cardiac biomarkers was increased when compared with baseline group. $(\mathrm{P}=0.000)$ (Table2).

The average numbers of high risk patients were 37 in baseline and 42 in four groups. There was not much difference in survival of patients at hospital discharge between the groups $(P=0.307)$. The proportion of patients undergoing CAG/PCI was high $(80.6 \%)$ in four groups but was not statistically significant when 
compared with baseline group (70.3\%). Door-to-needle time was not significantly decreased in four groups than baseline group. Door-to-balloon time was quiet variant in all groups because there were less number of patients undergoing primary $\mathrm{PCl}$ in baseline and I groups (Table2).

\section{Medical management}

On admission and during discharge, use of aspirin and clopidogrel, statin, $\beta$-blocker, and ACEI in by ACS patients in four groups were higher but not statically significant when compared with baseline. Similarly, the standard optimal medical therapy (Aspirin + Clopidogrel $+\beta$-blocker + ACEI or ARB + Statin), during admission and discharge, was received by most of the patients in each group (table 3 )

Table.3 Medical Management of the ACS patients

\begin{tabular}{|c|c|c|c|c|c|c|c|}
\hline \multirow[t]{2}{*}{ Treatment } & \multicolumn{5}{|c|}{ Groups } & \multirow{2}{*}{$\begin{array}{l}\text { Four } \\
\text { groups } \\
\text { (mean) }\end{array}$} & \multirow[t]{2}{*}{ P value } \\
\hline & baseline & I & II & III & IV & & \\
\hline \multicolumn{8}{|l|}{ During hospitalization } \\
\hline Aspirin (\%) & 98 & 98 & 100 & 98 & 100 & 99.0 & 0.731 \\
\hline Clopidogrel (\%) & 92 & 100 & 98 & 100 & 100 & 99.5 & 0.016 \\
\hline$\beta$-Blocker $(\%)$ & 72 & 80 & 80 & 92 & 84 & 84.0 & 0.134 \\
\hline Statin $(\%)$ & 100 & 98 & 98 & 100 & 98 & 98.5 & 0.731 \\
\hline ACEI or ARB $(\%)$ & 96 & 90 & 92 & 98 & 94 & 93.5 & 0.471 \\
\hline $\begin{array}{l}\text { Antiplatelet }+\beta \text {-Blocker }+ \text { statin }+(\text { ACEI } \\
\text { or ARB })(\%)\end{array}$ & 68 & 76 & 74 & 90 & 84 & 81.0 & 0.065 \\
\hline \multicolumn{8}{|l|}{ During discharge } \\
\hline Aspirin (\%) & 98 & 98 & 94 & 96 & 92 & 95.0 & 0.520 \\
\hline Clopidogrel (\%) & 96 & 92 & 96 & 96 & 90 & 93.5 & 0.680 \\
\hline$\beta$-Blocker (\%) & 72 & 72 & 70 & 88 & 72 & 75.5 & 0.210 \\
\hline Statin $(\%)$ & 98 & 96 & 94 & 100 & 90 & 95.0 & 0.134 \\
\hline ACEI or ARB $(\%)$ & 88 & 84 & 86 & 94 & 84 & 87.0 & 0.544 \\
\hline $\begin{array}{l}\text { Antiplatelet }+\beta \text {-blocker }+ \text { statin }+(\text { ACEI } \\
\text { or ARB) }(\%)\end{array}$ & 62 & 62 & 62 & 80 & 70 & 68.5 & 0.220 \\
\hline
\end{tabular}

Correlation between TIMI risk score and invasive therapy (PCI) There was negative correlation between TIMI risk score for (NSTEM/UA) patients and invasive therapy $(\mathrm{PCI})$ (Correlation coefficient $\mathrm{rs}=-0.312, \mathrm{P}=0.003$ ) (table 4). Inverse relationship between baseline risk score and the intensity of investigations or intervention, indicating the patient having low TIMI risk score were more likely undergoing cardiac catheterization $(\mathrm{PCI})$.

Table.4 Spearman's rank correlation coefficient test of TIMI risk score for NSTEMI/UA and invasive therapy (PCl)

\begin{tabular}{|l|l|}
\hline Correlation coefficient rs & P value \\
\hline-0.312 & 0.003 \\
\hline
\end{tabular}

\section{Comparison of treatment modalities between Xiangya third hospital and tertiary hospitals of china}

Use of clopidogrel (99.3\%) and statin (98.7\%) in ACS patients during admission was significantly higher $(P=0.000$ and $P=0.002)$ respectively, when compared with other china's tertiary hospitals (Fig.8). Doorto-needle time was shorter but door-to-balloon time was longer in our center compared with nationwide 
hospitals. Similarly, patients receiving $\beta$-Blocker, ACEI/ARB were also higher. The use of combination of drugs like antiplatelet, $\beta$-Blocker, ACEI/ARB, and stain was higher in Xiangya hospital compared with other nationwide tertiary hospitals (Table.5) .

Table.5 Comparison of treatment modalities between Xiangya third hospital and tertiary hospitals of china.

\begin{tabular}{|l|l|l|l|}
\hline Treatment Modalities & $\begin{array}{l}\text { Xiangya third hos- } \\
\text { pital }\end{array}$ & $\begin{array}{l}\text { Tertiary } \\
\text { hospitals of } \\
\text { China }\end{array}$ & P value \\
\hline Average Door-to-needle time (minutes) & 45.4 & 61 & \\
\hline Average Door-to-balloon time (minutes) & 128 & 90 & \\
\hline Use of Aspirin during hospitalization (\%) & 98.7 & 98.1 & 0.561 \\
\hline Use of Clopidogrel during hospitalization (\%) & 99.3 & 63.0 & 0.000 \\
\hline Use of $\beta$-Blocker during hospitalization (\%) & 84.0 & 74.7 & 0.115 \\
\hline Use of ACEI/ARB during hospitalization (\%) & 93.3 & 87.2 & 0.157 \\
\hline Use of Statin during hospitalization (\%) & 98.7 & 88.5 & 0.002 \\
\hline $\begin{array}{l}\text { Use of Antiplatelet + } \beta \text {-blocker + statin }+ \\
\text { (ACEI or ARB) in STEMI and NSTEMI pa- } \\
\text { tients (\%) }\end{array}$ & 68.4 & 60.0 & 0.150 \\
\hline
\end{tabular}

\section{DISCUSSION}

We observed after the implementation of clinical pathway the percentage of STEMI patients arriving within 12 hours of onset of symptoms was increased when compared to baseline group due to public awareness and quick transportation.

Drugs (Aspirin, ACEI/ARB, $\beta$-Blocker, statin) and its combination used by ACS patients were higher but not statically significant because of evidence based Practice. Most of the patients received all the drugs excluding some. The results were also consistent with other studies. ${ }^{12}$ The use of clopidogrel and statin were significantly higher, similarly patients receiving $\beta$-Blocker, ACEI/ARB, and the combination of these two drugs with antiplatelet, $\beta$-Blocker, were also higher compared with other hospitals. Dual antiplatelet therapy was avoided those who were on warfarin, Gl bleeding, and allergy to it.

Door-to-needle time in this hospital was not significantly different when compared with baseline group. The large European studies were also limited to: first medical contact to fibrinolysis time was 30 to 110 minutes and first medical contact to primary $\mathrm{PCl}$ was between 60 to 177 minutes. ${ }^{13}$ There was great variability in door-to-balloon time.

Door-to-needle time (45 minutes) was shorter than tertiary hospitals of china (61 minutes) because of presence of dedicated cardiologist. And there was increased in number of patients with significant reduction in reperfusion time in one of the European study. ${ }^{14}$ Door-to-balloon time (128 minutes) was longer than tertiary hospitals ( 90 minutes) may be due financial problem of the patient and busy CATH LAB. Time frame of $<90$ minutes was only achieved by $75 \%$ of patients in United States brought to $\mathrm{PCl}$ centers. ${ }^{15}$ The other study also have same result. ${ }^{16} \mathrm{PCl}$ in high risk patients was low due complication that made reluctant to invasive therapy. Other Europe and North American and national registries have same results. ${ }^{17}$

Even though the number of high risk patients was higher but there was no significan t change in mortality due to following clinical pathways and practicing evidence-based medicine. Decrease in mortality with good and qualitative patient care has been seen in other studies. ${ }^{18}$ 
Risk factors like age, male sex, smoking, and dyslipidemias were common and leads to ACS. ${ }^{19}$ Similarly, hypertensions, diabetes mellitus type 2 leading risk factors for $C A D, C K D$, peripheral vascular disease, stroke, and have significant mortality and morbidity. ${ }^{20}$

\section{CONCLUSION}

Implementation of Clinical pathway may help to improve patient outcome with early invasive and medical therapy

\section{REFERENCES}

1. Yusuf S, Reddy S, Ounpuu S, et al. Global burden of cardiovascular diseases: part I: general considerations, the epidemiological transition, risk factors, and impact of urbanization[J]. Circulation 2001;104:2746-2753.

2. He J, Gu D, Wu X, et al. Major causes of death among men and women in China[J]. N Engl J Med 2005;353:1124-1134.

3. Wu ZS, Yao $\mathrm{CH}$, Zhao $\mathrm{D}$, et al. Sino-MONICA Project, A collaborative study on trends and determinants in cardiovascular diseases in China, Part I: Morbidity and mortality monitoring[J]. Circulation 2001;103:462-468.

4. Randomized trial of intravenous streptokinase, oral aspirin, both, or neither among 17,187 cases of suspected acute myocardial infarction: ISIS-2. ISIS-2(Second International Study of Infarct Survival) Collaborative Group[J]. Lancet 1988;2:349-360.

5. Yusuf S, Zhao F, Mehta SR, et al. Clopidogrel in Unstable Angina to Prevent Recurrent Events Trial Investigators. Effects of clopidogrel in addition to aspirin in patients with acute coronary syndromes without ST-segment elevation [J]. N Engl J Med 2001;345:494-502

6. Antman EM, Anbe DT, Armstrong PW, et al. ACC/AHA guidelines for the management of patients with ST-elevation myocardial infarction: a report of the American College of Cardiology/ American Heart Association Task Force on Practice Guidelines (Committee to Revise the 1999 Guidelines for the Management of Patients with Acute Myocardial Infarction)[J]. Circulation 2004;110:82-292.

7. Wright RS, Anderson JL, Theroux P, et al. 2011 ACCF/AHA Focused Update of the Guidelines for the Management of Patients With Unstable Angina/ Non-ST-Elevation Myocardial Infarction (Updating the 2007 Guideline): a report of the American College of Cardiology Foundation/ American Heart Association Task Force on Practice Guidelines. Circulation [J] 2011;10:20222060.

8. Rumsfeld JS. Health status and clinical practice: when will they meet? Circulation 2002; 106:5-7.

9. Spertus JA, Jones $\mathrm{P}, \mathrm{McD}$ onell $\mathrm{M}$, et al.Health status predicts long-term outcome in outpatients with coronary disease. Circulation 2002;106:439.

10. Alpert JS, Thygesen K, Antman E, Bassand JP. Myocardial infarction redefined--a consensus document of The Joint European Society of Cardiology/American College of Cardiology Committee for the redefinition of myocardial infarction [J]. J Am Coll Cardiol;, 2000;36:959969

11. Braunwald E. Unstable angina: A classification[J]. Circulation, 1989, 80: $410-414$.

12. Gao R,Patel A, Gao W, et al. Prospective observational study of acute coronary syndromes in China:practice patterns and outcomes[J]. Heart 2008;94:554-560.

13. Widimsky P, Wijns W, Fajadet J, de Belder etal. Reperfusion therapy for ST elevation acute myocardial infarction in Europe: description of the current situation in 30 countries [J]. Eur Heart J 2010;31:943-957

14. Schiele $F$, Hochadel $M$, Tubaro $M$, et al. Reperfusion strategy in Europe: temporal trends in performance measures for reperfusion therapy in ST-elevation myocardial infarction[J]. Eur Heart J 2010;31:2614-2624.

15. Jacobs AK. Regional systems of care for patients with ST-Elevation myocardial infarction: being at the right place at the right time[J]. Circulation, 
2007, 116: 689-692.

16. Spencer FA, Montalescot G, Fox KA, et al. Delay to reperfusionin patients with acute myocardial infarction presenting to acute care hospitals: an international perspective[J]. Eur Heart J 2010;31:1328-1336.

17. Fox KA, Anderson FA Jr, Dabbous OH, et al. GRACE investigators. Intervention in acute coronary syndromes: do patients undergo intervention on the basis of their risk characteristics? The Global Registry of Acute Coronary Events (GRACE) [J]. Heart 2007; 93:177-182.
18. Mehta RH, Montoye CK, Gallogly BA, et al.Improving quality of care for acutemyocardial infarction:The Guidelines Applied in Practice(GAP) Initiative. JAMA 2002;287:1269-1276.

19. Uhl GS, Farrell PW. Myocardial infarction in young adults: risk factors and natural history[J]. Am Heart J 1983;105: 548-553.

20. Brindle P, Emberson J, Lampe F, et al. Predictive accuracy of the Framingham coronary risk score in British men: Prospective cohort study[J]. BMJ 2003;327:1267. 